and the succeeding Lower Chharat (early Khirthar) beds mark a fluviatile interlude before the extensive mid-Eocene transgression brought marine beds (Upper Chharats, Kohat Limestones, etc.) again over that region.

Thus the presence of Tertiary forms in the Punjab Salt Marl proves a Tertiary age for the associated salt, while the stratigraphy of the region more precisely indicates a basal Khirthar age for both the Punjab and the Kohat salt. Prof. Sahni's abundant confirmation of the first point goes far to clinch an increasingly strong case.

\section{Garscube Terrace,}

L. M. Davies.

Murrayfield, Edinburgh, 12.

${ }^{2}$ Nature, 153, 462 and 654 (1944).

2 Bull. Geol. Soc. Amer., 38, 665 (1927).

${ }^{3}$ Rec. Geol. Surv. Ind., 68, 117 (1933). Mr. Pinfold and I have since shown that Ranikot beds are well represented on the Salt Range, vide Nature, 139, 414 (1937); Pal. Indica (N.S.), 24, Mem. 1 (1937).

‘Trans. Min. Geol. Inst. Ind., 24, 202 (1929) ; Rec. Geol. Surv. Ind., 65, 112 (1932).

s"Geographical Changes in North-West India during Late Cretaceous and Early Tertiary Times", Proc. Sixth Pac. Sci. Congress, 1939 2, $483(1940)$.

IN a letter dated February 10, one of us directed attention to the discovery of microscopic angiosperm, gymnosperm and insect remains in the Saline Series as exposed in the salt mines at Khowra and Warchha in the Punjab. The situations from which our samples were taken, in the body of a closely bedded series, placed it beyond doubt that the fossils were truly in situ; and their affinities make it obvious that the beds cannot possibly be as old as Cambrian.

These fossils were obtained by dissolving two kinds of samples: (a) lumps of rock-salt in which thin interbedded layers of saline earth ('kallar') were enclosed, and $(b)$ portions of the 'kallar' bands alone, after scraping off the pure salt from both faces. We have now dissolved (c) lumps of the massive transparent rock-salt alone, taken from the same spots as before in the two mines. The Warchha salt has revealed shreds of carbonized pitted wood, and thickwalled tracheids with large circular separate bordered pits of the coniferous type. The Khewra salt has yielded, inter alia, felt-like masses of fibres of several different kinds; a fragment of wood with pitted cells; a cuticle recalling that of grasses, with a beautifully preserved stoma in an epidermis of elongated cells; and the chitinous coat of a small arthropod with paired jointed legs and traces of mouth parts.

Thus the rock-salt itself seems to be as rich in organic remains as the interbedded laminæ of saline earth. The indications are that the entire salt- and -'kallax' series in these mines is teeming with microfossils. For anyone now to claim that these fossils are 'derived' would be to claim that the whole series, even in the depths of these mines, has been churned up with extraneous matter. We cannot, of course, say whether the fossils reported by others were truly in situ. Ours certainly are; and although their exact age-value still needs to be critically assessed, there can obviously be no question of an age as ancient as Cambrian. On present evidence the only alternative seems to be that the Salt Marl is Tertiary.

B. SAHNI.

B. S. Trivedr.

Department of Botany and Geology,

University, Lucknow. April 19.

\section{Preparation of a Stable and Active Pancreatin from Commercial Samples}

THE problem of a pancreas protease preparation of a oonstant activity can be solved by the following preparative process :

l gm. of the commercial sample of 'Pancreatin' (Parke, Davis and Co.) is mixed with $10 \mathrm{ml}$. distilled water and kept under toluene for about 24 hours at $37^{\circ}$. The mixture is then centrifuged, filtered and $50 \mathrm{ml}$, absolute alcohol are added. The centrifuged precipitate obtained may be washed with ether and is dried in a vacuum desiccator over sulphuric acid.

The yield of the dried substance is about 10 per cent of the original commercial product. It dissolves easily in water and is about five times as active as the original water extract (casein as substrate).

The preparation retains also the lipase (of weak activity) and the amylase of the mother substance.

While the water extracts or even the generally used glycerol extracts are not stable and their activity diminishes gradually on standing, even when kept under toluene (water extracts) in an ice box, the dry preparation seems to retain its original activity indefinitely.

Chemical Department,

Jacob Fetgenbaum.
Cancer Research Laboratories,
The Hebrew University, Jerusalem.
March 3.

\section{A Basic Principle Governing the Changes in Organisms under the Action of External Factors}

THE present communication describes a general method of making a quantitative estimation of the response to external factors shown by biological systems of different order (individuals, taxonomic categories, populations or communities).

In studying the effect of training and learning, psychologists were the first to raise the question con. cerning the relationship of a change in the character to its original value ${ }^{1}$. In my recent, work published in collaboration with my associate Dr. Gause ${ }^{2}$ we gave three examples of "a negative relation between acquired and inherent characters of the organism".

My method consists in calculating the regression coefficients of positive or negative increments $(\Delta x)$ of the character on their original values $(x)$, both variables being expressed in the original units of measurement.

Four types of such a regression under the influence of an external factor can be established:

TABLE 1.

\begin{tabular}{|l|l|r|}
\hline $\begin{array}{c}\text { Change in size of } \\
\text { character }\end{array}$ & $\begin{array}{c}\text { Relation of increase } \Delta x \\
\text { to character }\end{array}$ & Type \\
\hline Increase & $\begin{cases}\text { Positive correlation } \\
\text { Negative , }\end{cases}$ \\
Decrease & Negative , & II \\
Positive, & III \\
\end{tabular}

The crossing of the $x$ axis by the regression line determines the point where $\Delta x$ is equal to 0 . This 